\title{
Introduction to Selected Contributions from GeoProc, The 5th International Conference on Coupled Thermo-Hydro- Mechanical-Chemical Process in Geosystems Held in Salt Lake City, Utah, from February 25-27, 2015
}

\author{
Robert Podgorney $^{1} \cdot$ John McLennan $^{2} \cdot$ Hai Huang ${ }^{1} \cdot$ Milind Deo $^{2}$
}

Published online: 23 February 2017

(c) Springer-Verlag Wien 2017

This special issue of Rock Mechanics and Rock Engineering contains papers that are a representative sample of contributions from GeoProc, The 5th International Conference on Coupled Thermo-Hydro-Mechanical-Chemical Process: Petroleum and Geothermal Reservoir Geomechanics and Energy Resource Extraction.

This triennial multidisciplinary international meeting sponsored by the International Society for Rock Mechanics (ISRM) was designed to bring scientists and engineers together from different backgrounds to address common scientific issues for a wide range of coupled natural and engineering phenomena, largely centered on energy resource extraction. GeoProc is a focal point for professionals and students from a wide variety of backgrounds, such as civil, geological, mining, geophysical and petroleum engineering, who to seek to understand and find solutions for coupled thermal-hydro-mechanical-chemical problems.

The manuscripts presented address a range of topics ranging from shale plasticity to hydraulic fracturing, and high-performance computing approaches, to simulate such phenomenon. The papers presented include field-relevant study, laboratory experiments, and investigations empowered by high-performance computing. The papers contained in this special issue were selected by members of the GeoProc organizing committee based on the quality of the technical content of the symposium papers. All papers were expanded and rewritten, then re-reviewed for this special issue.
Robert Podgorney

robert.podgorney@inl.gov

1 Geothermal Energy, Idaho National Laboratory, 2525

Fremont Ave, Idaho Falls, ID 83402, USA

2 University of Utah, Salt Lake City, UT, USA 